\title{
REFLEXÕES E CONSTATAÇÕES ACERCA DA IMPORTÂNCIA DA EDUCAÇÃO AMBIENTAL NO ÂMBITO EMPRESARIAL
}

\author{
Carla Noli Bisco Flozi ${ }^{1}$ \\ Fábio Freitas dos Santos ${ }^{2}$ \\ Angélica Góis Morales ${ }^{3}$
}

\begin{abstract}
RESUMO
No contexto empresarial, a educação ambiental cada vez mais se torna necessária, a fim de promover o desenvolvimento da sociedade transformando o ser humano em um responsável crítico com as questões socioambientais, além de contribuir com a conservação e preservação ambiental, bem como na minimização do impactos gerados ao meio ambiente. $O$ presente artigo teve como objetivo refletir sobre a educação ambiental no âmbito empresarial e sua importância, a fim de tecer possíveis constatações. Para tanto, realizou-se uma pesquisa qualitativa exploratória, buscando-se uma reflexão crítica sobre essa temática, uma vez que as questões ambientais são fatores relevantes nas organizações. Para o desenvolvimento do estudo, optou-se por uma pesquisa bibliográfica, a fim de contribuir no estado da arte da educação ambiental no âmbito empresarial, com foco no mapeamento das pesquisas já realizadas nesse contexto. Os resultados obtidos permitiram concluir que ainda existem entraves e lacunas ao se tratar de educação ambiental empresarial em especial no contexto brasileiro, que as dificuldades estão principalmente na falta de fundamentação teórica a respeito de EA e na preocupação em cumprimento formal da certificação.
\end{abstract}

PALAVRAS-CHAVE: Educação Ambiental. Gestão Empresarial. Meio ambiente.

\section{REFLECTIONS AND FINDINGS ON THE IMPORTANCE OF ENVIRONMENTAL EDUCATION IN BUSINESS SCOPE}

\footnotetext{
${ }^{1}$ Mestranda em Agronegócio e Desenvolvimento pela UNESP/Câmpus de Tupã. Graduada em Administração pelo Unisalesiano de Araçatuba. Membro do Grupo de Pesquisa em Gestão e Educação Ambiental (PGEA). E-mail: carlanbflozi@gmail.com.

${ }^{2}$ Mestrando em Agronegócio e Desenvolvimento pela UNESP/Câmpus de Tupã. Graduado em Biologia pela Faculdade "Auxilium" de Filosofia, Ciências e Letras em Lins. Membro do Grupo de Pesquisa em Gestão e Educação Ambiental (PGEA). E-mail: fabio.freitas@outlook.com.br.

${ }^{3}$ Docente da Universidade Estadual Paulista "Júlio de Mesquita Filho" (UNESP). Doutora em Meio Ambiente e Desenvolvimento pela Universidade Federal do Paraná (UFPR). Mestra em Educação Ambiental pela Fundação Universidade Federal de Rio Grande (FURG). Licenciada em Ciências Biológicas pela Universidade Estadual Paulista (UNESP). Líder do Grupo de Pesquisa em Gestão e Educação Ambiental (PGEA). E-mail: angelica@tupa.unesp.br.
} 


\title{
ABSTRACT
}

In the business context, environmental education increasingly becomes necessary in order to promote the development of society transforming the human being in a critical responsibility with social and environmental issues, and contribute to environmental conservation and preservation, as well as to minimize the impacts to the environment. This article aims to reflect on environmental education in the business sector and its importance in order to weave possible evidence. Therefore, there was an exploratory qualitative research, seeking a critical reflection on this theme, since environmental issues are relevant factors in organizations. To develop the study, we opted for a literature search in order to contribute to the state of the art environmental education in the business sector, focusing on the mapping of research already carried out in this context. The results showed that there are still barriers and gaps when it comes to environmental business education particularly in the Brazilian context, the difficulties are mainly the lack of theoretical basis about EA and concern formal compliance certification.

KEY-WORDS: Environmental Education. Business Management. Environment.

\section{REFLEXIONES Y CONCLUSIONES SOBRE LA IMPORTANCIA DE LA EDUCACIÓN AMBIENTAL EN ÁMBITO EMPRESARIAL}

\begin{abstract}
RESUMEN
En el contexto de los negocios, la educación ambiental es cada vez más necesario para promover el desarrollo de la sociedad transformando al ser humano en una responsabilidad fundamental de las cuestiones sociales y ambientales, y contribuir a la conservación del medio ambiente y la conservación, así como para minimizar el los impactos en el medio ambiente. Este artículo tiene como objetivo reflexionar sobre la educación ambiental en el sector empresarial y su importancia con el fin de tejer una posible evidencia. Por lo tanto, hubo una investigación cualitativa exploratoria, en busca de una reflexión crítica sobre este tema, ya que las cuestiones ambientales son factores relevantes en las organizaciones. Para desarrollar el estudio, se optó por una búsqueda de la literatura con el fin de contribuir al estado de la técnica de educación ambiental en el sector empresarial, centrándose en la cartografía de la investigación que ya se lleva a cabo en este contexto. Los resultados mostraron que todavía hay barreras y brechas cuando se trata de la educación de negocios del medio ambiente en particular en el contexto brasileño, las dificultades son principalmente la falta de base teórica sobre la EA y la certificación del cumplimiento formal de preocupación.
\end{abstract}

PALABRAS-CLAVE: Educación Ambiental. Administración De Empresas. Medio Ambiente.

\section{INTRODUÇÃO}

Atualmente os impactos ambientais negativos são resultados da falta de gerenciamento por longos períodos quanto a exploração dos recursos naturais. No âmbito empresarial, a gestão ambiental pode contar com o auxílio da educação ambiental, no intuito de contribuir com a redução de tais impactos negativos, por meio de seus princípios educativos e suas aplicações práticas. Frente a isso, denota a possibilidade das empresas atuarem um pouco mais de forma consciente e 
sustentável, contribuindo com a formação dentro das organizações, referente ao meio ambiente (SALES; CANTARINO, 2011).

Pela caminhada histórica, é perceptível que o ser humano mantinha um relacionamento com o ambiente por meio de dominação. Contudo, na atualidade, o ser humano não pode ser o centro do Universo. Perante a esse contexto torna-se fundamental uma reformulação de pensamento, de atitudes, com base crítica e reflexiva (MORALES, 2008).

Nessa necessidade de refletir sobre a relação entre ser humano e natureza, nota-se que a qualidade do meio ambiente proporciona de maneira direta a qualidade de vida ao indivíduo, que por sua vez reflete nas ações sociais, econômicas e políticas que são colocadas em prática. Deste modo, as questões ambientais possuem relevância e não convém serem tratadas de modo superficial, já que repercute diretamente na vida dos seres vivos. Além de que, as gerações futuras necessitam serem educadas ambientalmente, bem como as gerações atuais que necessitam de uma transformação educacional quanto às questões ambientais, tornando-se mais conscientes. Para tanto, a educação ambiental, se faz necessário nos ambientes escolares, empresarias e todos os demais setores da sociedade, a fim de que possa contribuir para que todos sejam educados para com o meio ambiente (MORALES, 2008).

Mas quando inicia-se essa preocupação em relação a questão ambiental? Sabe-se que problemas ambientais sempre existiram, mesmo que em menor proporção, porém foi a partir da Revolução Industrial que se originou a intensificação sob a preocupação com o meio ambiente, devido a exploração dos recursos naturais. Nesse sentido, Seiffert (2007, p. 17) salienta que desde então se observa que "a capacidade do ser humano em se alterar o meio ambiente havia aumentado significativamente, levando a consequências positivas e negativas e evidenciando uma interdependência entre a economia e o meio ambiente". Uma evidente contribuição se deu também por meio das Conferências Mundiais, como em 1972 que aconteceu a Conferência das Nações Unidas sobre o Ambiente Humano em Estocolmo, no qual foi enfatizado discussões sobre o crescimento populacional e métodos de desenvolvimento. Bem como medidas para controle dos danos ambientais, de modo especial à poluição emitida pelo complexo industrial. 
Novas maneiras integradas de articular as questões ambientais passou-se a serem difundidas, devido à necessidade na mudança de pensamento e postura quanto ao meio ambiente e ao desenvolvimento. Dessa forma, as empresas também são chamadas para penar as questões ambientais. Pode-se destacar em especial na década de 1980, a propagação do conceito de Responsabilidade Social Corporativa, no qual a área ambiental se fortaleceu por meio das Organizações Não Governamentais (ONGs), o que proporcionou considerável contribuição para as empresas (PEDRINI, 2008).

No âmbito empresarial a educação ambiental vem conquistando notoriedade, como pode ser visto em alguns estudos desse panorama como o de Vieira (2004) e o de Pedrini e Pelliccione (2007), que abordam a temática educação ambiental com ênfase nas empresas no cenário brasileiro. Logo, fica perceptível por meio desses estudos, a evolução e a entrada da dimensão ambiental nas empresas, embora ainda de forma lenta e pontual.

Um dos fatores de sobrevivência das empresas pode-se dizer ser o cliente, e este por sua vez tem alterado os hábitos de consumo, o que impulsionou muitas organizações a implantarem um sistema de gestão ambiental, que inserido a este sistema estão os programas sociais e de educação ambiental, o que agrega valor à sustentabilidade. Vale esclarecer que o conceito de gestão ambiental pode ser entendido, segundo Seiffert (2007, p.23):

[...] como um processo adaptativo e contínuo, através do qual as organizações definem, e redefinem, seus objetivos e metas relacionadas à proteção do ambiente, à saúde de seus empregados, bem como clientes e comunidade, além de selecionar estratégias e meios para atingir esses objetivos num tempo determinado através de constante avaliação de sua interação com o meio ambiente externo.

Frente ao exposto, a educação ambiental pode ser uma mediadora na implantação de processos de gestão ambiental no âmbito da empresa. Portanto, esse trabalho tem como objetivo investigar como a educação ambiental está presente na gestão em âmbito empresarial e qual sua importância nesse setor, a fim de uma reflexão e possíveis constatações.

Portanto, esse estudo teve como objetivo geral refletir sobre a educação ambiental no âmbito empresarial e sua importância. 


\section{METODOLOGIA}

Esta pesquisa é de caráter qualitativo e utiliza procedimentos metodológicos para focar a interpretação dos fenômenos, no contexto particular em que ocorrem (MIGUEL, 2007).

A metodologia empregada é uma pesquisa exploratória, que parte de uma pesquisa bibliográfica baseada em livros, artigos científicos, periódicos eletrônicos e legislação aplicada.

O referencial teórico deste estudo foi construído por meio de pesquisa bibliográfica sobre a educação ambiental no âmbito empresarial, articulando com a Gestão Ambiental (GA) e o Sistema Integrado de Gestão (SIG). Com as pesquisas foi possível mapear e conhecer os resultados das investigações cientificas, bem como aos atores e ações envolvidos nesse cenário construindo parcialmente o estado da arte da educação ambiental empresarial. Por fim, relata-se as características, as reflexões e constatações acerca das pesquisas realizadas sob o foco da educação ambiental e sua importância no âmbito empresarial.

\section{RESULTADOS}

Sobre as características e/ou fatores que exercem impactos positivos ou negativos no desenvolvimento da educação ambiental empresarial no contexto brasileiro, os elementos principais elencados neste estudo são:

- A percepção de que se está tendo uma aplicação conceitual da educação ambiental adequada, o que nem sempre acontece no âmbito empresarial.

- As práticas pedagógicas empresariais apresentam ausência de fundamentação teoria a respeito da educação ambiental e certa superficialidade didática.

- A escolha e definição dos métodos adequados, levando em consideração a cultura, os valores e o meio ambiente, para a realização da parte prática dos treinamentos (Gestão Ambiental).

- Do ponto de vista relacional, os colaboradores às vezes podem criar oposição devido alguns conflitos existentes entre os setores e, principalmente suas (más) impressões a respeito de quem ministra o treinamento, caso este seja um dos seus pares. 
- Comumente, há uma sobrecarga de tarefas a serem cumpridas aos participantes, acarretando acúmulo de atividades e falta de tempo para cumpri-las com eficácia e quanto aos não participantes revela-se cada vez mais um maior distanciamento, sendo um fator altamente desestimulante.

Pedrini e Pellicione (2007) ao desenvolverem uma pesquisa sobre metodologia para avaliar a qualidade do conceito da educação ambiental empresarial no Brasil (EAEB), no setor petrolífero, chegaram a oito atributos conceituais: a) emancipatório; transformador; c) participativo; d) abrangente; e) permanente; f) contextualizador; g) ético; h) interdisciplinar. Os autores concluíram que somente $45 \%$ dos índice de qualidade conceitual (IQC) foram adequados. Assim, pode-se verificar que a educação ambiental empresarial no setor petrolífero apresenta conceituação deficiente e nesse caso dificilmente contribuirá para a construção de sociedades sustentáveis conforme prevê o PRONEA.

Buscando-se a percepção de tendências e aspectos pedagógicos da educação ambiental, Adams e Gehlen (2008) observaram, num estudo realizado em quinze empresas de ramos de atuação diversos e de diferentes estados brasileiros, que é necessário, pois, um aprimoramento das atividades educacionais no ambiente empresarial e que a formação dos responsáveis pela educação ambiental das empresas se relaciona com as áreas das Ciências Sociais Aplicadas ou Exatas. Nesse sentido, com os resultados obtidos verificou-se que há: a) deficiências pedagógicas na implementação da educação ambiental; b) falta de referenciais teóricos de educação ambiental; c) baixo grau de reflexão nos aspectos didáticopedagógicos.

Fritzen e Molon (2008) trouxeram em seu estudo reflexões sobre o processo de capacitação do público interno durante a implantação de um SGA com base na ISO 14001, em uma empresa do setor petroquímico do Rio Grande do Sul, e fizeram uma interface com o processo de educação ambiental. A análise foi dividida em quatro categorias: a) treinamento b) mudança c) conscientização d) participação. No entanto, a empresa demonstrou fragilidade no discurso da EA, pois os resultados evidenciaram as dificuldades encontradas pela empresa frente ao cumprimento formal da normativa, o estabelecimento da conscientização e o envolvimento dos colaboradores durante o desenrolar das etapas do processo. 
Pelliccione, Pedrini e Kelecom (2008) também analisaram a respeito das práticas de educação ambiental em empresas da região sudeste brasileira certificadas com a ISO 14001 de Gestão Ambiental. Um questionário de pesquisa foi enviado via e-mail a 630 empresas, porém apenas 29 responderam o questionário. Grande parte entende que EA como um sinônimo de ações mitigadoras de seus impactos. As empresas demonstraram que não realizam os pressupostos da educação ambiental para sociedades sustentáveis no contexto empresarial, pois a maioria absoluta dos índices de qualidade conceitual não foram identificados e desconhecem o tratado de educação ambiental para sociedades sustentáveis e o programa nacional de educação ambiental. Essas evidências sugerem que o maior parque industrial brasileiro (região sudeste brasileira) é constituído de práticas de conteúdo conceitual fraco e ações de eficácia duvidosa com caráter conservacionista.

\subsection{GESTÃO EMPRESARIAL E GESTÃO AMBIENTAL}

No decorrer dos últimos anos, diversas discussões referente ao meio ambiente vem sendo debatidas, com o intuito de minimizar os impactos ambientais causados pelo homem. As demandas da sociedade conexas ao zelo com o meio ambiente têm impulsionado as empresas conduzirem esforços para ajustar suas atividades, com propósito de minimizar ou até mesmo eliminar impactos ambientais negativos.

É nesse panorama, que as empresas estão cada vez mais aderindo estratégias que envolvam as questões ambientais em seus planejamentos, ajustando seu modo de gestão, o que implica poder adotar uma política específica que contemple a prioridade das questões ambientais. Assim a gestão da organização passa a inserir, em seus projetos, planos e objetivos, as externalidades provindas de suas operações.

A gestão empresarial acompanha a modernidade em suas práticas de gestão e hoje, a eficiência torna-se imprescindível, em que minimiza-se os custos e maximiza-se os resultados. Porém, congregado a essa missão da gestão inclui-se a preocupação com as questões ambientais a fim de uma articulação do meio 
ambiente aos objetivos e estratégias das empresas, visando o lucro e a redução de impactos ambientais negativos, como o consumo consciente de matéria-prima, a coleta seletiva, os investimentos em tecnologias para uma produção mais limpa, entre outros.

Para lidar com as questões ambientais, as empresas aderem a gestão ambiental, que de acordo com Dias (2006), sua finalidade consiste em diagnosticar problemas ambientais oriundos pelas atividades das empresas, analisar critérios de atuação quanto suas normas e diretrizes, aderindo práticas atuais e condizentes a fim de minimizar ou eliminar seu passivo ambiental. Todo esse processo é realizado por um conjunto de medidas e procedimentos inseridos na gestão ambiental, o que reforça as empresas aderirem uma postura mais responsável e envolvida com as questões ambientais.

Com a busca da certificação ISO 14001, intensificou ainda mais a atenção sobre as questões ambientais nas empresas e, diversas delas iniciaram 0 desenvolvimento de um Sistema de Gestão Ambiental (SGA). Este sistema representa um papel crucial a ser desempenhado, onde proporciona conscientização e motivação aos envolvidos, com as ações de comprometimento de modo enfático a política ambiental da empresa, e por meio destas ações o objetivo sai do papel e ganha vida sendo parte da realidade das empresas.

Na gestão ambiental faz-se necessário um processo de educação ambiental, que contribui para que a empresa possa atingir os benefícios da gestão implantada, dos programas existentes e outras práticas pertinentes às questões ambientais (SILVA, 2010).

De acordo com Palavizini (2011), o propósito da educação ambiental consiste em ofertar o conhecimento legal e metodológico, que visa buscar de uma atuação técnica e social interativa, qualificada e consciente.

Portanto, a implementação de um Sistema de Gestão Ambiental (SGA) requer articulação das práticas e ações educativas em todo o complexo da empresa. Sendo assim, todos os setores estarão envolvidos com as questões ambientais e juntos podem pensar em elaborar soluções e intervenções criativas para o meio ambiente dentro da empresa.

Com objetivo em assegurar resultados mais eficientes com a implementação de um Sistema de Gestão Ambiental (SGA), a empresa deve desenvolver uma 
abordagem integrada em sua estrutura organizacional, em que a gestão ambiental atuará com outra gestão ou outras existentes na organização.

Para Vasconcelos e Melo (2007) um Sistema Integrado de Gestão (SIG) pode ser definido como, um conjunto de elementos (processos, práticas e procedimentos) inter-relacionados implementados na empresa para criar as políticas e seus objetivos, e para assentir que os objetivos sejam alcançados de maneira mais eficiente, visto que se houver diversos sistemas individuais sobrepondo-se existirá delongas na eficiência".

A integração de um sistema de gestão representa muito mais do que apenas inserir elementos de normas em um sistema já estruturado (FRESNER e ENGELHARDT, 2004 apud SATOLO, 2008).

Um Sistema Integrado de Gestão comumente integra práticas bem sucedidas para aprimorar continuamente o desempenho sustentável, ético e responsável das empresas nas esferas econômica, ambiental, social e na saúde ocupacional, devido a isso as normas referem-se a NBR ISO 9001 que trata sobre a qualidade, a NBR ISO 14001 representada pelo meio ambiente, a norma OHSAS 18001 sobre a saúde e segurança ocupacional, por fim a norma SA 8000 que fala sobre a responsabilidade social, como visualizado na figura 1.

Figura1: Modelo de Sistema Integrado de Gestão

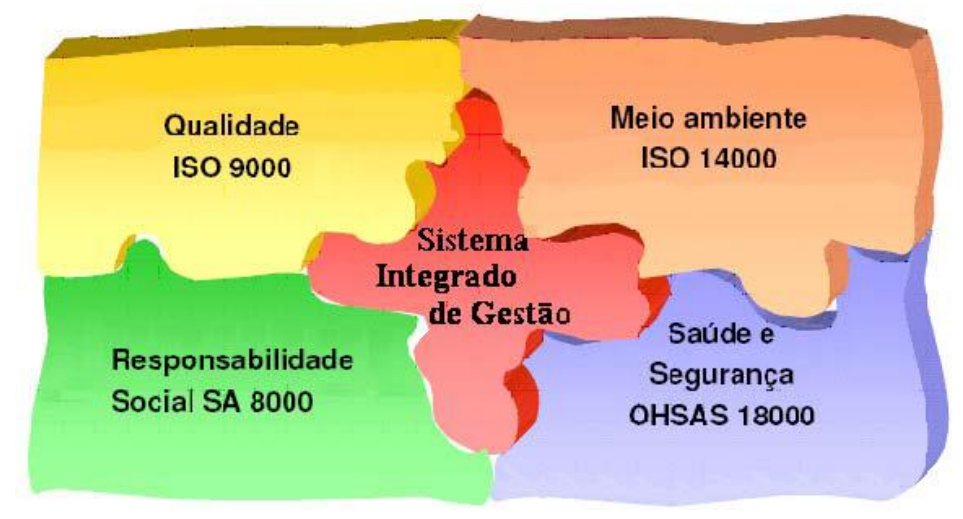

Fonte: SATOLO, p.4 2008.

As empresas que possuir sistemas com base nessas normas devem ser articuladas, devido as vantagens oriundas dessa integração, como planejamento e coordenação por meio da utilização de procedimentos comuns para determinadas 
questões. E o que se espera como resultado é a obtenção de sinergia entre as normas e as práticas laborais (BARBIERE, 2011).

A sinergia que se tem como objetivo a ser alcançado, requer ainda, que a gestão integrada considere a gestão de recursos humanos, visto que a inserção da variável ambiental, bem como as demais na empresa proporciona alterações em toda a organização em especial na conscientização das pessoas, em sua cultura e novo modo de produção (JABBOUR; SANTOS 2006).

Para avigorar a importância da gestão ser integrada, Donaire (1999, p. 102) afirma que "se a empresa pretende implantar a gestão ambiental em sua estrutura organizacional, deve ter em mente que seu pessoal pode transformar-se na maior ameaça ou no maior potencial para que os resultados esperados sejam alcançados".

A tabela 1 demonstra a importância segundo os autores nela descritos, da integração entre a gestão de pessoas e a gestão ambiental.

Tabela 1: Pesquisas que ressaltam a relevância da integração entre administração de recursos humanos e gestão ambiental

\begin{tabular}{|l|l|}
\hline \multicolumn{1}{|c|}{ Pesquisa } & \multicolumn{1}{|c|}{ Contribuição para a área de conhecimento } \\
\hline Azzone e Noci (1998) & $\begin{array}{l}\text { A geração de inovações sustentáveis demanda suporte dos } \\
\text { programas e práticas da gestão de recursos humanos. }\end{array}$ \\
\hline $\begin{array}{l}\text { Azzone, Bertelè e Noci } \\
(1997)\end{array}$ & $\begin{array}{l}\text { Vinculação entre o posicionamento ambiental da empresa e o } \\
\text { desenvolvimento de recursos humanos. }\end{array}$ \\
\hline Boiral (2002) & $\begin{array}{l}\text { Demonstra a importância do conhecimento tácito para a gestão } \\
\text { ambiental e as formas de administração desse conhecimento. }\end{array}$ \\
\hline $\begin{array}{l}\text { Boudreau e Ramstad } \\
\text { (2005) }\end{array}$ & $\begin{array}{l}\text { Ressaltam a importância da gestão de recursos humanos para a } \\
\text { efetiva contribuição organizacional ao desenvolvimento } \\
\text { sustentável. Para os autores, essa integração engendra um novo } \\
\text { paradigma para a tomada de decisões em recursos humanos. }\end{array}$ \\
\hline $\begin{array}{l}\text { Brío e Junquera } \\
\text { (2003) }\end{array}$ & $\begin{array}{l}\text { Na maioria das pequenas empresas, a falta de programas e } \\
\text { práticas de gestão de recursos humanos adequadas entravam a } \\
\text { efetiva implementação de programas de gestão ambiental. }\end{array}$ \\
\hline $\begin{array}{l}\text { Buysse e Verbeke } \\
\text { (2003) }\end{array}$ & $\begin{array}{l}\text { Reconhecimento dos recursos humanos como elementos } \\
\text { determinantes do estágio evolutivo da estratégia ambiental da } \\
\text { empresa. }\end{array}$ \\
\hline Corazza (2003) & $\begin{array}{l}\text { Ressalta a importância das práticas da gestão de recursos } \\
\text { humanos para a integração matricial da dimensão ambiental na } \\
\text { empresa. }\end{array}$ \\
\hline $\begin{array}{l}\text { Fernández, Junquera } \\
\text { e Ordiz (2003) }\end{array}$ & $\begin{array}{l}\text { Propõem, de forma pioneira, um modelo integrado entre as fases } \\
\text { do sistema de gestão ambiental e os fatores de recursos } \\
\text { humanos. } \\
\text { Desenvolvem uma perspectiva teórica integrada entre a gestão } \\
\text { ambiental na empresa e os elementos da cultura organizacional, }\end{array}$ \\
\hline
\end{tabular}




\begin{tabular}{|l|l|}
\hline & $\begin{array}{l}\text { evidenciando o papel da gestão de recursos humanos para o } \\
\text { desenvolvimento de uma cultura pró-gestão ambiental. }\end{array}$ \\
\hline Harris e Crane (2002) & $\begin{array}{l}\text { Discutem as principais barreiras para a interiorização da dimensão } \\
\text { ambiental na cultura organizacional. }\end{array}$ \\
\hline $\begin{array}{l}\text { Triana e Ortolano } \\
(2005)\end{array}$ & $\begin{array}{l}\text { Exploram a relação entre aprendizagem organizacional e } \\
\text { desempenho de programas de gestão ambiental. }\end{array}$ \\
\hline Vickers (2005) & $\begin{array}{l}\text { A gestão de recursos humanos como indutora de um } \\
\text { comportamento ambiental ético nas organizações. }\end{array}$ \\
\hline Wee e Quazi (2005) & $\begin{array}{l}\text { Constatam que práticas de gestão de recursos humanos são } \\
\text { fatores críticos da gestão ambiental empresarial. }\end{array}$ \\
\hline Wehrmeyer (1996) & $\begin{array}{l}\text { Ressalta a abordagem integrada entre dimensões funcionais da } \\
\text { gestão de recursos humanos e os programas de gestão ambiental } \\
\text { nas empresas. }\end{array}$ \\
\hline $\begin{array}{l}\text { Wilkinson, Hill e Gollan } \\
\text { (2001) }\end{array}$ & $\begin{array}{l}\text { Importância da gestão de recursos humanos para o alinhamento } \\
\text { das práticas }\end{array}$ \\
\hline Zutshi e Sohal (2004) & $\begin{array}{l}\text { Indicam as dimensões da gestão de recursos humanos como o } \\
\text { principal grupo de fatores críticos de sucesso para a adoção e } \\
\text { manutenção de sistemas de gestão ambiental. }\end{array}$ \\
\hline
\end{tabular}

Fonte: Adaptação de Jabbour; Santos, 2007.

As pesquisas apresentadas na tabela 1 , demonstram que realmente as pessoas são recursos valiosos para as organizações.

Ainda que pesquisas foram e continuam sendo desenvolvidas sob o enfoque gestão integrada, alguns resultados demonstram que o caráter de integração possui falhas. Um estudo realizado por Alperstedt; Quintella e Souza (2010), revelou de acordo com sua amostra - 88 empresas catarinenses de diversos segmentos agrupadas em duas categorias (grande porte e PMEs - pequeno e médio portes), que ao menos $50 \%$ das duas categorias estão inseridas no mercado internacional e possuem Gestão Ambiental (GA), $90 \%$ é o percentual das grandes empresas e $62,5 \%$ das PMEs. Contudo as políticas de Gestão Ambiental Integradas (GAI) são expressas em maior proporção às grandes empresas com $45 \%$, enquanto as PMEs com $27,1 \%$.

Os resultados deste estudo, confirmaram os pressupostos de seus autores, no qual suspeitavam que as empresas de grande porte teriam maior representatividade quanto as práticas mais avançadas em sua gestão ambiental integrada (ALPERSTEDT; QUINTELLA; SOUZA, 2010).

Todavia, denota-se que as organizações parecem estar buscando nova postura de atitudes mais comprometida, proativa e conscientizada com as questões 
ambientais, o que faz com que as seja implementado o processo permanente em educação ambiental para alcançar de modo eficiente tal objetivo.

\subsection{EDUCAÇÃO AMBIENTAL EMPRESARIAL}

A educação ambiental é um processo educativo que, conforme Sorrentino (2005, p. 288), "conduz a um saber ambiental materializado nos valores éticos e nas regras políticas de convívio social e de mercado, que implica a questão distributiva entre benefícios e prejuízos da apropriação e do uso da natureza".

A educação ambiental é evidentemente um fato mundial e que se tornou obrigatória no Brasil pela Lei no 9.795/99, o qual institui a Política Nacional de Educação Ambiental, que contribui para que as empresas também possam buscar atuar na dimensão socioambiental.

No contexto empresarial a educação ambiental desempenha um importante papel no desenvolvimento da sociedade e, de modo direto influencia a sociedade na redução dos impactos representados por danos ambientais, o que aos poucos incorpora na imagem corporativa sua responsabilidade, e consequentemente, agrega valor perante o mercado de consumo. Com essa postura pode influenciar outras empresas, comunidade, escolas por meio das ações realizadas voltadas ao meio ambiente.

Contudo, muitas empresas ainda, são impulsionadas a entrar na questão ambiental apenas devido ao licenciamento ambiental e, não reconhecem a aplicação direta dos estudos ambientais desenvolvidos, e sua responsabilidade e comprometimento com o meio ambiente possui fragilidades (BRASIL, 2008).

Porém, sabe-se que as empresas possuem participação fundamental quanto ao desenvolvimento de programas de educação ambiental, o que reforça a parceria e cooperação entre empresas, escolas e a sociedade. Diversas empresas no Brasil estão implantando programas de educação ambiental, porém, quanto a análise dos programas quanto sua eficiência necessita de estudos (MACEDO; VARGAS, 2011).

Subentende-se também que, algumas empresas não possuem em sua estrutura e cultura organizacional as práticas ambientais devido a educação ambiental envolver complexidade em seu processo, visto que a mesma deve trabalhar as vertentes: social, econômica, política, cultural e ecológica. O trabalho da educação ambiental será fruto de transformação de um novo ser humano integrado 
ao meio ambiente, rompendo com a tradição segmentada e reducionista (MACEDO; VARGAS, 2011).

Contudo, essa transformação que condiz com a postura dos colaboradores para com o meio ambiente é um desafio para as empresas, requer tempo, exige o envolvimento das pessoas, o compartilhamento do saber ambiental, com objetivo em construir de modo coletivo as novas concepções, atitudes e responsabilidades ambientais (LEITE; MEDINA, 2001).

\section{CONCLUSÕES}

Conclui-se que os entraves encontrados pelas empresas no que se refere ao processo de Educação Ambiental têm sido a tônica do momento, pois os resultados demonstram certa dificuldade e fragilidade ao se tratar de educação ambiental empresarial.

Os resultados demonstram que na maioria das vezes há uma pseudo percepção da aplicação conceitual de educação ambiental, pois existem equívocos quanto à mesma, refletindo, assim em certa superficialidade em suas práticas pedagógicas devido uma notável ausência de fundamentação teórica das empresas quanto a educação ambiental.

Também no que se refere ao processo de gestão ambiental constata-se que as empresas tem se focado no cumprimento obrigatório das normas, dando ênfase à preocupação com as certificações do que para o desenvolvimento de habilidades e competências individuais e coletivas de seus colaboradores que poderiam refletir numa prática de educação ambiental abrangente.

Com os resultados apresentados neste artigo, pretende-se chamar a atenção sobre o modo que tem sido tratada a educação ambiental nas empresas, principalmente no Brasil e as lacunas que ainda existem em relação ao tema em discussão, o que implica em carência de estudos nesse segmento. 


\section{REFERÊNCIAS}

ADAMS, G. B.; GEHLEN, L. Contribuições Pedagógicas para a Educação Ambiental Empresarial. In PEDRINI, A. G. (Org.). Educação Ambiental Empresarial no Brasil, São Paulo: Rima Editora, 2008. p. 14-25.

ALPERSTEDT, G. D.; QUINTELLA, R. H.; SOUZA, L. R. Estratégias de gestão ambiental e seus fatores determinantes: uma análise institucional. Revista de Administração de Empresas (RAE). V. 50, n. 2, p. 170-186, abr./jun. 2010.

BARBIERE, J. C. Gestão ambiental empresarial: conceitos, modelos e instrumentos. 3. ed. São Paulo: Saraiva, 2011.

BRASIL. Ministério do Meio Ambiente. Política Nacional de Educação Ambiental. Lei n 9.795 , de 27 de abril de 1999, 2008. Disponível em:

<http://www.mma.gov.br/port/conama/legiabre.cfm?codlegi=321> Aceso em: 01 abr. 2015.

DIAS, R. Gestão ambiental: responsabilidade social e sustentabilidade. São Paulo: Atlas, 2006.

DONAIRE, D. Gestão ambiental na empresa. 2. ed. São Paulo: Atlas, 1999.

FRITZEN, F. M.; MOLON, S. I. Educação Ambiental e a Norma ISO 14001: O Processo de Capacitação sob a perspectiva do Público Interno. In: PEDRINI, A. G. (Org.). Educação Ambiental Empresarial no Brasil, São Paulo: Rima Editora, 2008. p. 26-38.

JABBOUR, C. J. C.; SANTOS, F. C. A. Evolução da gestão ambiental na empresa: uma taxonomia integrada à gestão da produção e de recursos humanos. Gestão e Produção, São Carlos, v. 13, n. 3, p. 435-448, 2006.

Desenvolvimento de produtos sustentáveis: o papel da gestão de pessoas. Rev. Adm. Pública [online], v. 41, n. 2, p. 283-307, 2007.

LEITE, A L. T., MEDINA N. M. Educação ambiental: curso básico a distância -questões ambientais: conceitos, história, problemas e alternativas. Brasília: MMA, 2001. 5 v, ed. ampliada.

MACEDO, S. R. K.; VARGAS, L. C. Educação Ambiental Empresarial: reflexão sobre os desafios da atuação no contexto escolar. AMBIENTE \& EDUCAÇÃO-Revista de Educação Ambiental, v. 15, n. 2, p. 209-228, 2011.

MIGUEL, P. A. C. Estudo de caso na engenharia de produção: estruturação e recomendações para sua condução. Produção. v. 17, n. 1, p. 216-229, 2007.

MORALES, A. G. Processo de institucionalização da educação ambiental. In: PARANÁ. Secretaria do Estado Da Educação. Superintendência de Educação. Departamento da Diversidade. Coordenação de Desafios Educacionais Contemporâneos. Educação ambiental. Curitiba: SEED, 2008. (Cadernos Temáticos da Diversidade, 1).

PALAVIZINI, R. Educação para a sustentabilidade: uma abordagem transdisciplinar. NUPEATIESA- UFG, v.1, n.1, jan./jun./2011 (p.25-35).

PELliCCIONE, N. B. B.; PEDRINI, A. de G.; KELECOM, A. C. Educação Ambiental Empresarial: uma avaliação conceitual de práticas no sudeste brasileiro. In: PEDRINI, A. G. (Org.). In:

Educação Ambiental Empresarial no Brasil. São Carlos: RiMa, 2008, p. 39-55.

PEDRINI, A. de G. Educação Ambiental Empresarial no Brasil. São Carlos: Rima, 2008.

PEDRINI, A. de G.; PELLICCIONE, N. B. B. Educação Ambiental Empresarial no Brasil: uma análise exploratória da sua qualidade conceitual. Mundo e Vida. Niterói, v.8, n.1, 2007. 
da Alta Paulista

SALES, T.; CANTARINO, A. Educação ambiental empresarial como ferramenta na gestão ambiental. In: VII CONGRESSO NACIONAL DE EXCELÊNCIA EM GESTÃO, 2011, Rio de Janeiro. Anais... Rio de Janeiro: FIRJAN-RJ, 2011. p. 1-22. Acesso em: 20 mar. 2015. Disponível em:

$<$ http://www.excelenciaemgestao.org/portals/2/documents/cneg7/anais/t11_0352_2183.pdf>.

SATOLO, E. G.; CALARGE, F. A. O emprego de sistema integrado de gestão na agroindústria sucroalcooleira: um estudo de caso na região de Piracicaba/SP. In: XXVIII ENCONTRO NACIONAL DE ENGENHARIA DE PRODUÇÃO, Rio de Janeiro. Anais... Rio de Janeiro, 2008. Acesso em: 19 mai. 2015. Disponível em:

http://www.abepro.org.br/biblioteca/enegep2008_TN_STO_069_490_10680.pdf

SEIFFERT, M. E. B. ISO 14001. Sistema de Gestão Ambiental: implantação políticas e economias. São Paulo: Atlas, 2007.

SILVA, L.F. As relações entre o conhecimento científico e educação ambiental crítica- contribuição metodológica das sociologias das ausências, das emergências e tradução. In: TRISTÃO, M.; JACOBI, P.R. Educação ambiental e os movimentos de um campo de pesquisa. Annablume, 2010. p. 223.

SORRENTINO, M. et al. Educação ambiental como política pública. Educação e Pesquisa, São Paulo, v. 31, n. 2, p. 285-299, 2005.

VASCONCELOS, D.S.C.; MELO, M.B.F.V. Aplicabilidade da especificação PAS 99:2006 como modelo de gestão: um estudo de caso. In: ENCONTRO NACIONAL DE ENGENHARIA DE PRODUÇÃO, 27, Foz do Iguaçu, Brasil, p. 1-9 anais, 2007.

VIEIRA, L. R. Metodologia de educação ambiental para indústria. São Carlos: Santaclara, 2004. 